chalk mixture, with myrrh. The hardness in the left part of the abdomen increasing. Continue the poultices.

9th.-Fluctuation perceptible. A lancet was introduced, and a quantity of flatus, with highly offensive frecal matter, discharged. - Evening: Much relieved; the opening discharging bloody fæculent matter. To continue the morphia dranght at bed-time.

10th.-Better in every respect; pulse 110, small. To have an ounce and a half of wine daily, with more nutritious diet.

From the last date up to the 3 rd of $J$ une the patient went on improving, the opening discharging only a small quantity of pus. On the 12th of June, the opening had quite closed, and the patient was rapidly regaining strength, but there still existed a slight hardness in the neighbourhood of the part injured. For this an ointment containing iodine and nitrate of mercury was ordered, and on the 19 th he presented himself at the surgery quite well.

Clay Cross, June 18, 1850.

\section{APPLICATION OF COLD AS AN ANAESTHETIC AGENT IN OPERATIONS FOR REMOVING WARTY EXCRESCENCES,}

Bx THOMAS W. NUNN,

SURGEON TO THE WESTERN DISPENSARY, \&C.

Dr. James Arnotr, of Brighton, suggested in the number of Tue Lancet for July 22, 1848, the employment of cold as an agent in destroying the sensibility of parts during operations, but the almost universal adoption of chloroform has prevented, as far as I know, any attempt at following out this method by the London surgeons.

There is a certain class of cases requiring an operation, which, although of the simplest nature, is nevertheless attended with apparently the most exquisite conceivable torture. I allude to the cases where warty excrescences on the genitals of either male or female have reached a size which renders their removal not only desirable, but absolutely necessary.

There are two objections to the employment of the vapour of chloroform in such instances. The first is, the slight nature of the operation; the second, the unseemly results which are liable to follow interference with the pudic nerve coincident with administration of chloroform. Moreover, chloroform cannot, or rather should not, be administered without the assistance of an experienced hand, and the presence of some two or three persons to hold the patient in case of need. All this may be exceedingly undesirable under the circumstances.

Taking these points into consideration, the employment of cold for the purpose of producing local anæsthesia seems especially indicated.

I have lately taken advantage of the hint given by Dr. Arnott, and have been so satisfied with the result, that I think I am only paying what is properly due to that gentleman in thus publishing the following case :-

A young married woman applied at the Western Dispensary for the purpose of being relieved of a large accumulation of wart growths about the pudenda. She had been an out-patient at one or two hospitals, she informed me, without an operation being proposed to her.

The excrescences depended from the whole of the labia minora, and surrounded the clitoris so completely, that it was difficult to distinguish the meatus urinarius. Some of them were of considerable size-as large as a common fig-others were oblong. and were attached by a narrow pedicle. A great many small ones surrounded the orifice of the vagina. She also suffered from leucorrhœal discharge. No other symptom of importance appeared. The excrescences were the cause of a great deal of suffering and inconvenience, in a variety of ways.

Assisted by my friend Mr. Weston, I applied little wedgeshaped pieces of ice to the necks of the larger growths, till they became perfectly blanched and cold, and with a single stroke of a curved probe, pointed bistoury, removed several of the larger ones successively, without causing the patient any but slight pain.

I afterwards removed a very small growth without first applying ice. The result was, as might have been anticipated, the patient found the pain insupportable.

I found it necessary to iutroduce a bougie into the urethra, in order to indicate the position of the external orifice of that canal, so buried was it amongst the vegetations.

A great advantage obtained by the use of the ice, was the absence of hæmorrhage; it being hardly requisite to apply a sponge during the operation. I was thereby enabled to proceed without hindrance, and a clear view was obtained of the exact extent of each sweep of the bistoury.

No reaction in the least degree excessive followed the proceeding, the progress of the case being satisfactory.

It appears to me, that by the above simple plan we may often save our patients considerable suffering, without exposing them to the least extra risk, which cannot be said of chloroform. It has been proved, on the one hand, over and over again, that if anresthesia be not COMPLETE, there is the contingency of undesirable phenomena; while, on the other hand, if the anæsthesia be perfect, a greater chance of accident is incurred.

Stratford-place, August 23, 1850.

\section{İospital Zeports.}

\section{BEDFORD COUNTY LUNATIC ASTLUM.}

(Reported by Benjamin Fielding Matthews, Esq., M.R.C.S., \&c. Resident Medical Officer.)

FATAT AFPHYXIA, FROM REGURGITATION OF VOMITED MATTER INTO THE LARYNX, TRACHEA, AND BRONCHI.

M. A. M-, aged thirty-five, a tall powerful woman, was admitted into the Asylum in December, 1844, labouring under chronic mania, with occasional paroxysms of great violence towards others. Her health, generally, was very good, till within the last eighteen months, when she has suffered, occasionally, from attacks of dyspncea. She has also had two fits of epilepsy during the last year. The last known attack occurred about four months ago. On the morning of the 21 st of December, 1849, information was brought to me that she had been found dead in the bed in her own sleeping department. I went immediately, and found her quite dead. By her side was a quantity of vomited matter; her head was bent forward on her chest; her fingers and hands were firmly clenched; there was considerable ecchymosis of the face and neck; the upper portions of the body were quite cold, but the lower extremities were warm. She had retired to bed the night before, in her usual state of health.

A utopsy, twenty-four hours after death.-The scalp was much congested; the skull was thicker than natural; the brain was slightly congested, otherwise it was healthy, with the exception of the corpus callosum, which was very soft. On opening the chest, the lungs did not collapse, and both of them were observed to be emphysematous, and in the trachea and ramifications of the bronchi was found a considerable quantity of dark greenish fluid, containing numerous small particles of bread, corresponding, in appearance, with that which had been vomited, and with the contents of the stomach. The heart and other viscera were healthy.

Since the occurrence of this case, my friend, $\mathrm{Mr}_{\mathrm{r}}$ George Yates, the house-surgeon to the Bedford General Infirmary, has favoured me with the particulars of a somewhat parallel case, which occurred some years ago, at the Birmingham Hospital.

G. H- aged thirty, a labourer, was admitted into the hospital, with a severe laceration of the right arm and fore-arm, and a compound fracture of the right thigh. Amputation, about two inches above the elbow-joint, was performed the same afternoon. The thigh was placed upon a double inclined plane of pillows. He passed a good night, but complained, on the following day, of a pain in the arm and thigh. In the evening he became restless, and talked of getting up, but was greatly relieved by an anodyne. He passed a good night. At nine o'clock on the following morning, the nurse was giving him some coffee, when he expressed a desire to get up: soon afterwards he cried out, "I am choked," and vomited a quantity of a dirty green viscid fluid, expiring shortly afterwards.

Autopsy, twenty-four hours after death.-The forehead and face were congested; the cellular tissue of the throat and scrotum were emphysematous; the thigh was found to be gangrenous; the brain was healthy; the lungs did not collapse on opening the chest; the trachea and ramifications of the bronchi were filled with a greenish fluid, not quite so dark as the vomited matters; the stomach contained a green pultaceous mass; the spleen was distended with blood; the other viscera were healthy.

Remarks.-In both the above cases, there can be no doubt that death arose from the presence of foreign matters in the trachea and bronchi. In the case under my care, I think that it is probable either that an attack of epilepsy came on during the act of vomiting, or that vomiting followed a fit of epilepsy, which 
I have frequently seen in epileptic patients. I have also frequently noticed an attack of epilepsy occur during meal-times, or shortly afterwards. In the case occurring in the Asylum, a coroner's inquest was held, and a rerdict of " accidental suffocation" returned.

\section{ZRebiems and Notices of ZBooks,

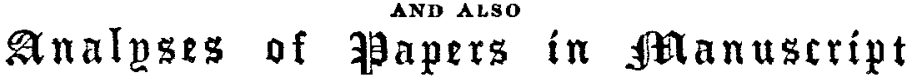 SENT FOR PUBLICATION IN THE LANCET.}

De la Folie causée par l'abus des Boissons Alcooliques. Par C. N. S. MARCeI, M.D., \&c. 4to., pp. 57. Paris. 1847.

The monograph of Dr. Marcel is not alone worthy of the attention of those whose practice is chiefly confined to insanity, but merits that of practitioners generally, since the subject of which it treats too often falls, alas! within the observation even of those whose experience of cases of pure mental aberration is not very extensive. M. Marcel admits that the immediate and primitive effects of an addiction to spirituous fluids have been, to a certain extent, studied, but not so fully as the secondary and remote ones, and which he endeavours to illustrate.

"These are very different from the former, having nothing in common with them but identity of origin. They are separated by a combination of characters which establishes a well-marked line of demarcation between them; in fact, we may say we have a new phase of alcoholic émpoisonnement."-p. 9.

Or again,

* A man gives himself up to excess of drinking; after a certain time he drinks less, but he becomes a madman. Here, as we see, there is no drunkenness, no acnte intoxication which directly induces the insanity. But the abuse of alcohol has modified his constitution, and it is this action, profound, distant, but persistent, which has induced the mental aberration."-p. 10.

The usual symptoms specially referred to are certain forms of hallucination, obscure ideas, tendency to suicide; the physical symptoms, febrile erethism, and agitation. Under proper treatment, the prognosis is favourable, but in two cases the author has known general paralysis to follow. The period of treatment is variable from some weeks to many months. For the nature of the treatment, and other interesting matter, we refer our readers to the work of M. Marcel himself, whose treatise we recommend.

The Symptomatic Treatment of Asiatic Cholera. By EwIng Whitrle, M.D., \&c. Small 8vo, pp. 100. London. 1850.

A shont treatise by one actively engaged in the treatment of the pestilence as it appeared in Liverpool during the last year. The chief conclusions arrived at by the author may be said to be the following. Cholera algida is in its nature a fever, of the continued congestive type. It has four stages, a stage of invasion, of spasm, of collapse, and of encephalic fever. It is an infectious disease, but to a less extent than most other epidemic infectious disorders. When the result of infection it generally assumes the most malignant type, and the security conferred by one attack against another, if any at all, is inconsiderable. The treatment recommended is the following:-in the premonitory diarrhcea, the persesquinitrate of iron with tincture of opium, or calomel and opium; in the next stage, warmth, sinapisms, and bleeding; and circumstances may require the iron and tartar-emetic to be given; in the stage of collapse, the principal reliance must generally be on the vis medicatrix nature, but in some cases bleeding, in others calomel, astringent enemata, and warmth, are useful. In the stage of encephalic fever, calomel, local bleeding from the head, and counter-irritation, \&c.
The principal object, however, of Dr. Whittle's Essay, is, to use his own words,

"To point out what appear to be the true indications for bleeding, and to enforce them by a faithful detail of the cases," \&c.-p. viii.

The Principles of Surgery. By J JMes MuLner. Second edition. 8vo, pp. 802. Edinburgh: Adam \& Charles Black. London : Longmans.

THE author, in this edition, has considerably added to the work, and the arrangement of the different subjects treated of has been made more complete. The size has been altered to the octavo form, and the volume altogether has a very handsome appearance. It is profusely illustrated with excellent wood-cuts. Mr. Miller's "Principles," unlike many works of this class, not only gives us the very ample experience of the author, but contains the latest information on all surgical points which have been published in this and other countries. If we were inclined to direct attention to any particular chapter of this valuable work, it would be that on the Constitutional Treatment of Surgical Diseases, in which the author treats this most interesting subject with remarkable ability. The chapter on Chloroform is also valuable; but we are surprised to see no reference to the extensive experience of Dr. Snow on this subject. It has been proved by this book. that the modern Athens is equal to the production of a work in all the requisites of type and illustration which may fairly rival the most carefully "got up" books of London.

Selection of Papers and Prize Essays on S̈ubjects Connected with Insanity. Read betore the Society for Improving the Condition of the Insane. 8vo. pp. 200.

Ir would appear, from the contents of this volume, that the Society from which it emanates has been assisted in its benevolent objects by some of the most eminent psychologists of the age. Among the contributors are Haslam, Morison, and Lockhart Robertson, who have severally written on restraint and coercion, the discrimination between crime and insanity, and an essay on the improvements made by the moderns on the medical treatment of mental diseases.

Annual Report of the Progress of Chemistry and the Allied Sciences, 1847-48. By Justus LieBIa and H. Kopp. Taylor \& Walton. 8vo.

To every person who is in any way connected with chemistry this work must be essential. It has been most carefully edited by Dr. Hoffman and Mr. De la Rue.

The New York Scalpel. No. VIII. For August. Suashing, spirited, and humorous. The Scalpel is as amusing as a novel: it loses none of its raciness.

Twentieth Annual Report of the Belfast District Lunatic Asylum, for the year ending the 31st of March, 1850 .

IrELAND, like England and Scotland, follows in the wake of improvement as to the treatment of lunatics and management of asylums. The official Reports published of several Irish establishments show this fact satisfactorily, and from the document whose title heads this article, we are induced to give one or two illustrations, which seem interesting, whilst they indicate the movements of a well regulated insane institution. During the year embraced in the above Report, 120 patients were admitted into the Belfast Asylum, the majority being females-63 females to 57 males; the recoveries reported being 24 males to 28 females, the deaths 25 males and only 18 females; hence the rate of mortality ranged higher among men, whereas more cures were effected in the other 